\title{
Enteral leucine supplementation increases protein synthesis in skeletal and cardiac muscles and visceral tissues of neonatal pigs through mTORC1-dependent pathways
}

\author{
Agus Suryawann, ${ }^{1,2}$, Roberto Murgas Torrazza ${ }^{1,2}$, Maria C. Gazzaneo ${ }^{1,2}$, Renán A. Orellana ${ }^{1,2}$, Marta L. Fiorotto ${ }^{1,2}$, \\ Samer W. El-Kadi ${ }^{1,2}$, Neeraj Srivastava ${ }^{1,2}$, Hanh V. Nguyen ${ }^{1,2}$ and Teresa A. Davis ${ }^{1,2}$
}

INTRODUCTION: Leucine (Leu) activates mammalian target of rapamycin (mTOR) to upregulate protein synthesis (PS).

RESULTS: PS in skeletal muscles, heart, liver, pancreas, and jejunum, but not kidney, were greater in low protein supplemented with Leu $(L P+L)$ than $L P$, but lower than high protein (HP). In longissimus dorsi muscle, protein kinase B phosphorylation was similar in $\mathrm{LP}$ and $\mathrm{LP}+\mathrm{L}$, but lower than HP. Although less than HP, p70 ribosomal S6 kinase 1 (S6K1) and eukaryotic initiation factor (elF) 4E binding protein 1 (4EBP1) association with regulatory associated protein of mammalian target of rapamycin was greater in $L P+L$ than $L P$, resulting in higher S6K1 and 4 EBP1 phosphorylation. Feeding LP+L vs. LP decreased 4EBP1•elF4E and increased elF4E.elF4G formation, but not to HP. Similar results were obtained for S6K1 and 4EBP1 phosphorylation in gastrocnemius, masseter, heart, liver, pancreas, and jejunum, but not kidney. elF2a and elongation factor 2 phosphorylation was unaffected by treatment.

DICUSSION: Our results suggest that enteral Leu supplementation of a low protein diet enhances PS in most tissues through mTOR complex 1 pathways.

METHODS: To examine enteral Leu effects on PS and signaling activation, 5 -d-old piglets were fed for $24 \mathrm{~h}$ diets containing: (i) $L P$, (ii) $L P+L$, or (iii) $H P$.

M any babies are born preterm, and, despite improvements in their care, their extrauterine growth frequently falters (1-3). Although premature infants may be initially provided parenteral nutrition, the goal is to initiate and advance enteral feeding (4). However, enteral feeding is often limited by concerns about the preterm infant's ability to metabolize nutrients and clinical complications related to feeding intolerance and necrotizing enterocolitis (5-7). Thus, enteral feeding may not achieve the level of protein required to sustain optimal growth.

To identify strategies to optimize the nutrition of neonates, we have used the neonatal pig as a model of the human infant. We found that feeding stimulates protein synthesis (PS) in skeletal muscle of neonatal pigs (8), and this response is independently mediated by the rise in insulin and amino acids (AAs) $(9,10)$. Leucine is the most effective single AA in triggering the activation of translation initiation factors that regulate muscle PS (11-16), but the effects of leucine in visceral tissues are not well understood. We have shown that parenteral AA infusion in neonates stimulates the intracellular signaling proteins that regulate PS (17); however, less is known about the effects of enteral AA delivery on the activation of this pathway.

AAs, especially leucine, serve as substrates for PS and also as nutrient signals to stimulate translation initiation (11-17). Unlike insulin, AAs do not activate protein kinase B (PKB) but activate the mammalian target of rapamycin (mTOR) $(16,18)$, which functions in two distinct protein complexes (mTOR complex 1 (mTORC1) and mTORC2) (19). mTORC1, a major player for mRNA translation, consists of several components, including regulatory associated protein of mTOR (raptor, an activator) and proline-rich Akt substrate of $40 \mathrm{kDa}$ (PRAS40, an inhibitor) (20), whose association is crucial for mTORC1 activation. Activated mTORC1 promotes eukaryotic initiation factor (eIF) 4E-binding protein 1 (4EBP1) and ribosomal protein S6 kinase-1 (S6K1) phosphorylation. Phosphorylated 4EBP1 allows active eIF4E.eIF4G complex formation and activated S6K1 phosphorylates ribosomal protein S6. Both processes are crucial for translation initiation (21).

Other crucial steps for mRNA translation are the eukaryotic initiation factor (eIF2) pathway (22) and the peptide elongation process. Phosphorylation of eIF2a (an inhibitor) is a limiting step in the eIF2 pathway, whereas elongation factor 2 (eEF2) phosphorylation regulates elongation (23). Insulin and AAs modulate eIF2 $\alpha$ and eEF2, resulting in PS progression.

Recently, we showed that enteral leucine supplementation of a low-protein meal acutely stimulates PS (24). However, it is unclear whether the effects could be sustained by prolonged enteral leucine supplementation. Although prolonged intravenous leucine infusion alone can reduce circulating levels of essential AAs, which can limit PS (17), whether this occurs with prolonged enteral leucine supplementation is unknown, as a decline in other AAs was not observed in our previous

'United States Department of Agriculture/Agricultural Research Service Children's Nutrition Research Center, Houston, Texas; ${ }^{2}$ Department of Pediatrics, Baylor College of Medicine, Houston, Texas. Correspondence: Teresa A. Davis (tdavis@bcm.edu) 
acute enteral leucine supplementation study (24). Therefore, the aims of this study were to determine whether feeding of a low-protein diet supplemented with leucine for $24 \mathrm{~h}$ can sustain enhanced rates of muscle and visceral tissue PS in neonatal pigs at rates similar to those achieved with a high-protein diet and to examine the mechanisms involved.

\section{RESULTS}

\section{Plasma Insulin, Glucose, and AAs}

Plasma insulin concentrations increased over time $(P<0.05)$ in a cyclic pattern with each bolus feed and returned to fasting levels by $4 \mathrm{~h}$ in all groups (Figure 1a). Insulin did not differ between the low protein (LP), LP supplemented with leucine $(\mathrm{LP}+\mathrm{L})$, and high protein $(\mathrm{HP})$ groups except at $1,530 \mathrm{~min}$ ( 90 min after the last meal) when insulin levels were higher in the HP group than in the LP or LP+L groups $(P<0.05)$. In all groups, blood glucose concentrations over time were similar (Figure 1b). Branched-chain AA (BCAA) concentrations changed with time in the three groups $(P<0.05)$ in a cyclic pattern with each bolus feed and returned to baseline after $4 \mathrm{~h}$, except for in the HP group (Figure 1c; $P<0.05$ ). BCAA concentrations at 1,530 min were higher in the $\mathrm{LP}+\mathrm{L}$ group than in the LP group but were lower than in the HP group $(P<0.05)$.

Plasma levels of most essential and nonessential AAs increased over time in the three groups $(P<0.05$; data not

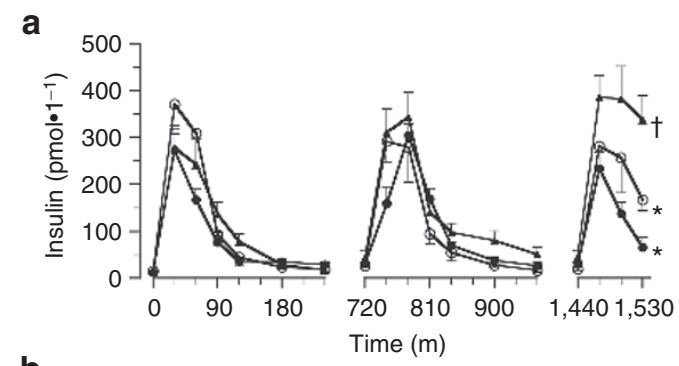

b
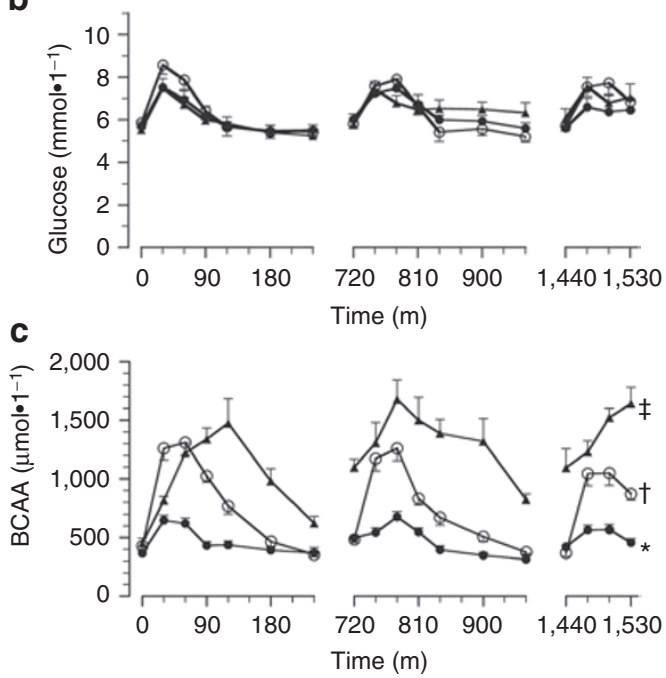

Figure 1. (a) Circulating insulin, (b) glucose, and (c) BCAA concentrations in piglets fed LP (filled circles), LP+L (open circles), and HP (filled triangles) diets every $4 \mathrm{~h}$ for $24 \mathrm{~h}$. Values are means $\pm \mathrm{SEM}, n=7-10$ per treatment. Means without a common symbol differ, $P<0.05$. BCAA, branched-chain amino acid; $H P$, high protein; $L P$, low protein; $L P+L$, $L P$ supplemented with leucine. shown). Most nonessential AAs at 1,530 min were similar in the $\mathrm{LP}$ and $\mathrm{LP}+\mathrm{L}$ groups but were greater in the HP group $(P<0.05$; Figure 2a); plasma glutamine levels were higher in the LP+L than the LP group $(P<0.05)$. Most essential AAs at 1,530 min were higher in the HP group than in the LP or $\mathrm{LP}+\mathrm{L}$ groups $(P<0.05$; Figure $2 \mathrm{~b})$. Plasma isoleucine and valine concentrations differed between groups at $1,530 \mathrm{~min}$ with lower levels in the $\mathrm{LP}+\mathrm{L}$ group $(P<0.05)$.

\section{PS and Signaling Components in Fast-Twitch, Glycolytic Muscle}

In the longissimus dorsi, a muscle containing primarily fasttwitch, glycolytic fibers, PS was greater in the HP group than in the LP or LP+L groups (Figure 3a), and PS was also higher in the $\mathrm{LP}+\mathrm{L}$ group than in the LP group $(P<0.05)$. PKB phosphorylation in the longissimus dorsi muscle was higher in the HP group than in the LP or LP+L groups $(P<0.05$; Figure $3 \mathbf{b})$. Phosphorylation of S6K1 and 4EBP1 was greater in the $\mathrm{LP}+\mathrm{L}$ group than in the LP group $(P<0.05)$ and was further increased in the HP group $(P<0.05$; Figures 3 c,d). The association of mTOR with raptor and of PRAS40 with raptor did not differ between groups (Figures 4a,b). However, the S6K1•raptor and $4 \mathrm{EBP} 1 \bullet$ raptor complexes were higher in the $\mathrm{LP}+\mathrm{L}$ group than in the LP group but did not reach the levels seen in the HP group $(P<0.05$; Figures $4 \mathbf{c}, \mathbf{d})$.

The abundance of $4 \mathrm{EBP} 1 \cdot \mathrm{eIF} 4 \mathrm{E}$ in the longissimus dorsi muscle was lower in the LP+L group than in the LP group but higher than in the HP group $(P<0.05$; Figure $5 \mathrm{a})$. The abundance of the active eIF4E $\bullet$ IF $4 \mathrm{G}$ complex was greater $(P<0.05)$ in the $\mathrm{LP}+\mathrm{L}$ group than in the LP group but was greater in the
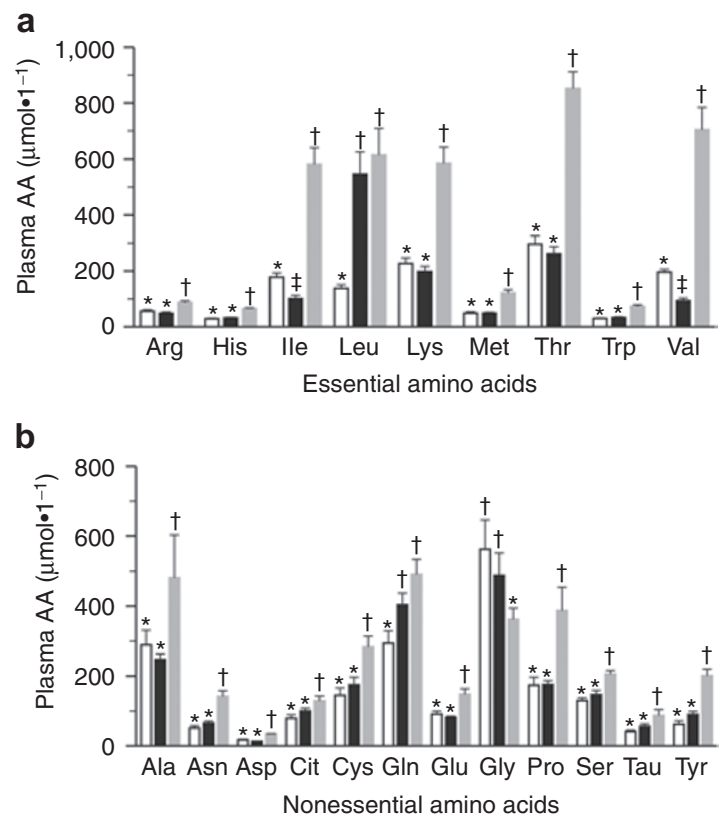

Figure 2. Plasma concentrations of essential (a) AAs and (b) nonessential AAs in piglets fed LP (open bars), LP+L (black bars), or HP (gray bars) diets for $1,530 \mathrm{~min}$. Values are means $\pm \mathrm{SEM}, n=7-10$ per treatment. ${ }^{*,+, *}$ Means for each $A A$ without a common symbol differ, $P<0.05$. AA, amino acid; $H P$, high protein; $L P$, low protein; $L P+L$, LP supplemented with leucine. 
a

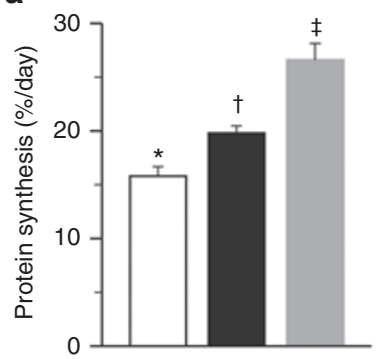

C

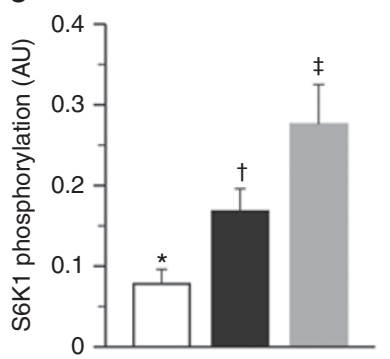

b

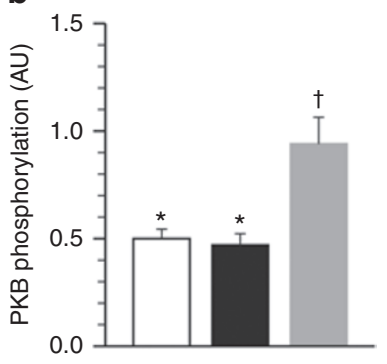

d

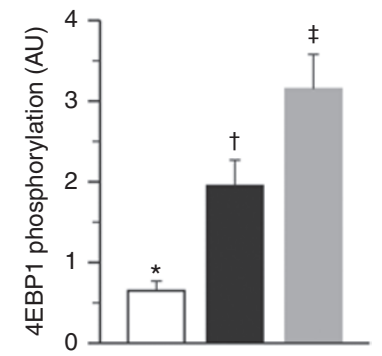

Figure 3. (a) PS rates and phosphorylation of (b) PKB, (c) S6K1, and (d) 4EBP1 in longissimus dorsi muscle of piglets fed LP (open bars), LP+L (black bars), or HP (gray bars) diets. Values are means \pm SEM, $n=7-10$ per treatment. ${ }^{*,+, \neq}$ Means without a common symbol differ, $P<0.05$. 4EBP1, eukaryotic initiation factor $4 \mathrm{E}$-binding protein $1 ; \mathrm{HP}$, high protein; $L P$, low protein; $L P+L$, LP supplemented with leucine; PKB, protein kinase $B$; PS, protein synthesis; S6K1, p70 ribosomal S6 kinase-1.

HP group ( $p<0.05$; Figure $5 b$ ). Phosphorylation of eIF $2 \alpha$ and eEF2 was unaffected by treatment (Figures $\mathbf{5} \boldsymbol{c}, \mathbf{d}$ ).

\section{PS and Signaling Components in Oxidative Muscles}

PS levels in gastrocnemius muscle, which contains mixed glycolytic and oxidative fibers; masseter muscle containing primarily oxidative fibers; and cardiac muscle, which has oxidative fibers, were greater in the $\mathrm{LP}+\mathrm{L}$ group than in the LP group but were greatest in the HP group $(P<0.05$; Figure 6). S6K1 and $4 \mathrm{EBP} 1$ phosphorylation in these tissues was greater in the $\mathrm{LP}+\mathrm{L}$ group than in the LP group $(P<0.05)$ but was highest in the HP group $(P<0.05$; Table 1$)$. There were no treatment effects on eIF2 $\alpha$ and eEF2 phosphorylation (Table 2).

\section{PS and Signaling Components in Visceral Tissues}

PS in liver, jejunum, and pancreas, but not kidney, was higher in the LP+L group than in the LP group but lower than in the HP group $(P<0.05$; Figure 7$)$. Leucine supplementation increased $\mathrm{S} 6 \mathrm{~K} 1$ and $4 \mathrm{EBP} 1$ phosphorylation in visceral tissues, except kidney, although not to levels seen in the HP group ( $P$ $<0.05$; Table 1). eIF2 $\alpha$ and eEF2 phosphorylation was unaffected by treatment (Table 2).

\section{DISCUSSION}

Postnatal nutrition has a critical impact on the long-term outcome of preterm infants (25). Short-term decreases in dietary intake are inevitable consequences in the complex care of preterm infants (26). Preterm infants frequently have poor tolerance to enteral feeding and thus consume a lower volume of
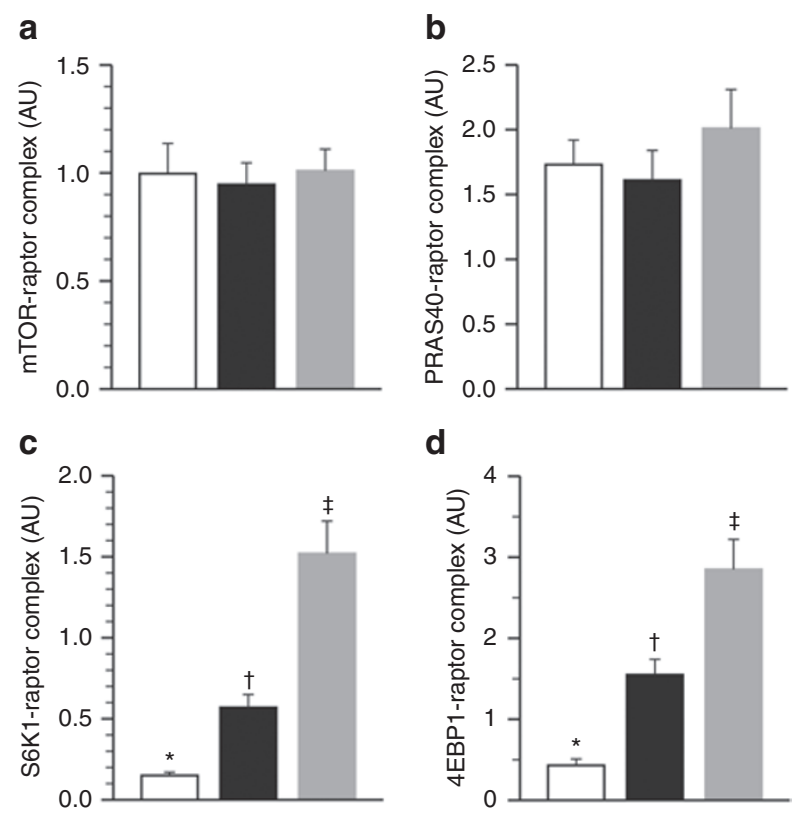

Figure 4. Abundance of (a) raptor.mTOR, (b) raptor.PRAS40, (c) raptor.56K1, and (d) raptor.4EBP1 complexes in longissimus dorsi muscle of piglets fed LP (open bars), LP+L (black bars), or HP (gray bars) diets. Values are means $\pm \mathrm{SEM}, n=7-10$ per treatment. ${ }^{*, t \neq}$. Means without a common symbol differ, $P<0.05$. 4EBP1, eukaryotic initiation factor $4 \mathrm{E}$-binding protein $1 ; \mathrm{HP}$, high protein; LP, low protein; $\mathrm{LP}+\mathrm{L}$, LP supplemented with leucine; mTOR, mammalian target of rapamycin; PRAS40, proline-rich Akt substrate of $40 \mathrm{kDa}$; S6K1, p70 ribosomal S6 kinase-1.

milk formula than that necessary to meet their protein requirements for adequate growth. Recently, we showed that feeding a meal of a low-protein milk formula supplemented with leucine as compared with a low-protein formula meal alone acutely increases PS in most tissues to rates similar to those achieved with a high-protein meal (24). In our current study, we wished to determine whether the anabolic response to leucine supplementation could be sustained for a more prolonged period. The results of this study indicate that prolonged leucine supplementation of a milk formula with a low-protein content can enhance PS as compared with the low-protein diet alone. Although the leucine-induced increase in PS was lower than that with a high-protein milk formula, our findings suggest a potential beneficial effect of including leucine supplementation in the nutritional management plan for sick premature infants. However, limitations of the study include the lack of a normal suckling pig control and the use of term rather than preterm piglets.

Previously, we showed that parenteral leucine infusion for $24 \mathrm{~h}$ reduced circulating levels of other AAs and limited the leucine-induced increase in PS, likely because other AAs were needed as substrates for PS (17). However, when the fall in other AAs was prevented by performing an AA clamp, the leucine-induced increase in PS was sustained. Recently, we found that acute enteral leucine supplementation of an LP meal did not elicit a fall in other AAs and yielded increased PS similar to that of a HP meal (24). In our current study, consumption of the $\mathrm{LP}+\mathrm{L}$ as compared with the LP diet for $24 \mathrm{~h}$ reduced circulating 
isoleucine and valine concentrations, likely due to activation of enzymes that metabolize BCAA, namely, branched-chain aminotransferase and branched-chain a-ketoacid dehydrogenase (27). Unlike in our previous acute enteral leucine supplementation study (24), the reduction in isoleucine and valine in our current study may be responsible for the failure to achieve maximum PS rates obtained with the HP diet. However, circulating insulin levels in our current study were higher in the HP than in the LP and LP+L groups, unlike our previous acute leucine supplementation study, and may have contributed to the higher PS rate, at least in muscle, but only in the HP group.

The positive effect of leucine administration on muscle PS in humans and animal models has been recognized (11-13,28). In this study, we determined effects of leucine supplementation on muscles of different fiber types including longissimus dorsi a

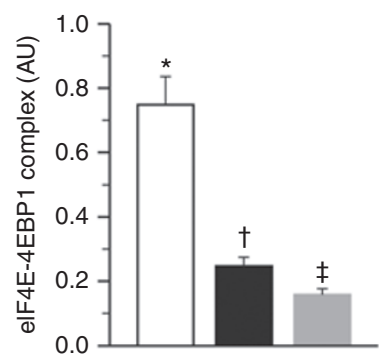

C

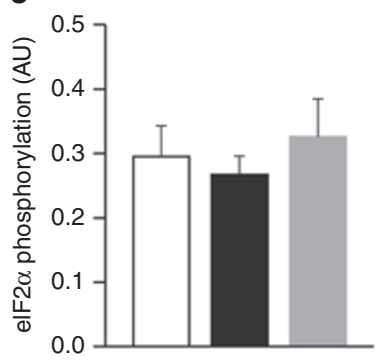

b

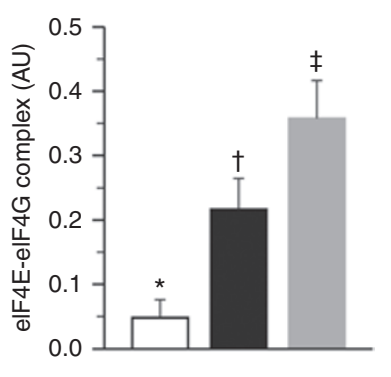

d

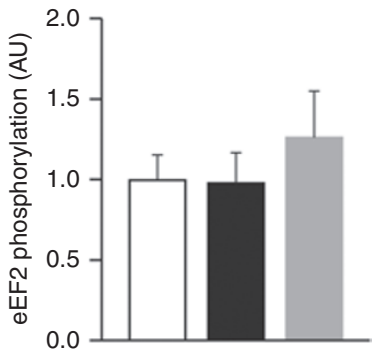

Figure 5. Abundance of (a) elF4E•4EBP1 and (b) elF4E•elF4G, and phosphorylation of (c) elF2a and (d) eEF2 in longissimus dorsi muscle of piglets fed LP (open bars), LP+L (black bars), or HP (gray bars) diets. Values are means $\pm \mathrm{SEM}, n=7-10$ per treatment. ${ }^{*,+, \neq}$ Means without a common symbol differ, $P<0.05 .4 \mathrm{EBP}$, eukaryotic initiation factor $4 \mathrm{E}$-binding protein 1; elF, eukaryotic initiation factor; HP, high protein; LP, low protein; $\mathrm{LP}+\mathrm{L}, \mathrm{LP}$ supplemented with leucine. (mainly glycolytic fibers), gastrocnemius (mixed glycolytic and oxidative fibers), masseter (oxidative fibers), and cardiac muscles (oxidative fibers). Consistent with our 24 -h parenteral leucine infusion study (17), in our current study enteral leucine supplementation stimulated PS in muscles of different fiber types, although the leucine effect was less potent than the HP diet, which was used as a positive control to elicit maximum PS rates. In our previous study, acute leucine supplementation of an LP meal enhanced PS in these muscles comparable with the HP meal (24), likely due to maintenance of isoleucine and valine levels.

To better understand the overall anabolic effect of leucine supplementation in neonates, we determined PS rates in visceral tissues. We showed that leucine supplementation enhanced PS in liver, pancreas, and jejunum but not kidney. In our previous 24-h parenteral leucine infusion study, the leucine-induced increase in PS was detected in liver and pancreas, although not jejunum or kidney, and only when AA availability was maintained (17). Differences between these two studies in the jejunum response could be due to the different route of leucine administration (i.e., parenteral vs. enteral). The lack of effect in the kidney may be due to rerouting excess AAs to gluconeogenesis (29).

To evaluate molecular mechanisms by which leucine stimulates PS in vivo, we determined the leucine-induced activation of signaling components leading to mRNA translation. More detailed study of signaling component activation was conducted in longissimus dorsi muscle. $\mathrm{PKB}$ activation is a hallmark for insulin-induced PS (30). Consistent with other studies $(16,18)$, we found that leucine supplementation had no effect on $\mathrm{PKB}$ activation in muscle. The recent consensus is that AAs, particularly leucine, stimulate PS in an mTORC1dependent pathway downstream of PKB (31), although the exact molecular mechanism is not completely understood. Phosphorylation of two major targets of mTORC1, S6K1 and $4 \mathrm{EBP} 1$, has been used as a readout for mTORC1 activation (31). Likewise, S6K1 and 4EBP1 association with mTORC1 through raptor is a bona fide indicator of MTORC1 activation (32,33). Cell culture studies suggest that mTOR-raptor association positively and PRAS40-raptor association negatively regulates mTORC1 activation (34). In our study, leucine supplementation enhanced S6K1 and 4EBP1 association
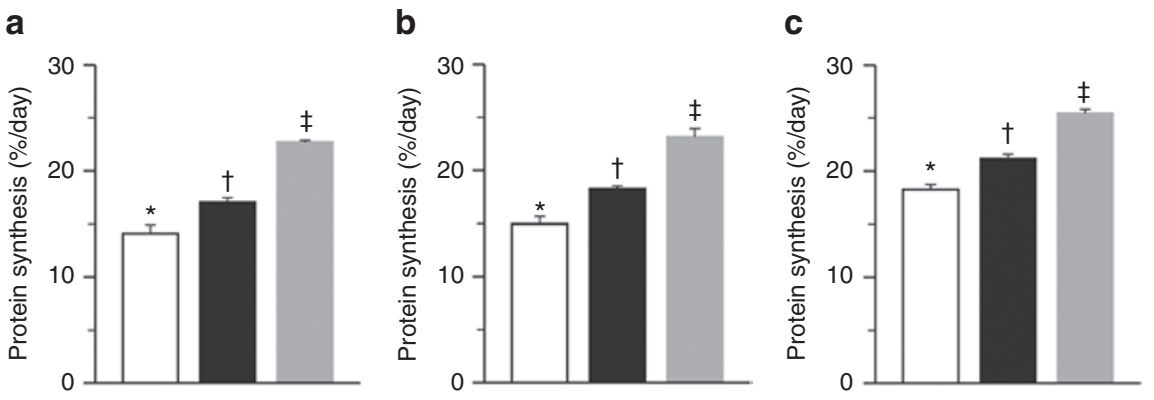

Figure 6. PS rates in (a) gastrocnemius, (b) masseter, and (c) heart muscles of piglets fed LP (open bars), LP+L (black bars), or HP (gray bars) diets. Values are means $\pm S E M, n=7-10$ per treatment. ${ }^{*},+, ., M e a n s$ without a common symbol differ, $P<0.05$. HP, high protein; $L P$, low protein; $L P+L$, $L P$ supplemented with leucine; PS, protein synthesis. 
Table 1. Phosphorylation of S6K1 and 4EBP1 in skeletal muscles and visceral tissues of piglets fed an LP, LP+L, or HP diet for $24 \mathrm{~h}$

\begin{tabular}{|c|c|c|c|c|c|c|}
\hline \multirow[b]{2}{*}{ Tissue } & \multicolumn{3}{|c|}{ S6K1 (AU) } & \multicolumn{3}{|c|}{ 4EBP1 (AU) } \\
\hline & LP & $\mathrm{LP}+\mathrm{L}$ & HP & LP & $\mathrm{LP}+\mathrm{L}$ & HP \\
\hline Gastrocnemius & $0.33 \pm 0.03^{*}$ & $0.63 \pm 0.08^{* *}$ & $1.04 \pm 0.11^{+}$ & $0.45 \pm 0.14^{*}$ & $0.68 \pm 0.09 * *$ & $0.95 \pm 0.11^{\dagger}$ \\
\hline Heart & $0.31 \pm 0.05^{*}$ & $0.54 \pm 0.06^{* *}$ & $0.79 \pm 0.11^{\dagger}$ & $0.29 \pm 0.09^{*}$ & $0.57 \pm 0.13^{* *}$ & $0.89 \pm 0.14^{+}$ \\
\hline Liver & $0.24 \pm 0.06^{*}$ & $0.48 \pm 0.09^{* *}$ & $0.79 \pm 0.14^{+}$ & $0.15 \pm 0.06^{*}$ & $0.32 \pm 0.07^{* *}$ & $0.58 \pm 0.11^{\dagger}$ \\
\hline Pancreas & $0.31 \pm 0.07^{*}$ & $0.59 \pm 0.12^{* *}$ & $0.90 \pm 0.13^{+}$ & $0.20 \pm 0.06^{*}$ & $0.52 \pm 0.09^{* *}$ & $0.79 \pm 0.13^{+}$ \\
\hline Kidney & $0.29 \pm 0.09$ & $0.37 \pm 0.09$ & $0.40 \pm 0.09$ & $0.59 \pm 0.10$ & $0.57 \pm 0.12$ & $0.69 \pm 0.15$ \\
\hline
\end{tabular}

Values are means \pm SEM, $n=7$ per group. If ANOVA $P<0.05$, post hoc test analysis was performed. ${ }^{*},{ }^{* *},{ }^{\dagger}$ Means in a row with superscripts without a common symbol for either $S 6 \mathrm{~K} 1$ or 4EBP1 differ, $P<0.05 .4 \mathrm{EBP} 1$, eukaryotic initiation factor 4E-binding protein 1; AU, arbitrary units; HP, high protein; LP, low protein; LP+L, LP supplemented with leucine; S6K1, p70 ribosomal 56 kinase-1.

Table 2. Phosphorylation of eEF2 and elF2a in other muscles and visceral tissues of piglets fed an $L P, L P+L$, or HP diet for $24 \mathrm{~h}$

\begin{tabular}{|c|c|c|c|c|c|c|}
\hline \multirow[b]{2}{*}{ Tissue } & \multicolumn{3}{|c|}{ eEF2 (AU) } & \multicolumn{3}{|c|}{ elF2a $(A U)$} \\
\hline & LP & $\mathrm{LP}+\mathrm{L}$ & $\mathrm{HP}$ & LP & $\mathrm{LP}+\mathrm{L}$ & $\mathrm{HP}$ \\
\hline Gastrocnemius & $0.87 \pm 0.19$ & $0.92 \pm 0.09$ & $1.01 \pm 0.11$ & $1.34 \pm 0.15$ & $1.19 \pm 0.19$ & $1.22 \pm 0.11$ \\
\hline Heart & $0.81 \pm 0.16$ & $0.93 \pm 0.14$ & $0.99 \pm 0.16$ & $0.99 \pm 0.12$ & $0.96 \pm 0.15$ & $0.94 \pm 0.14$ \\
\hline Liver & $1.25 \pm 0.12$ & $1.38 \pm 0.15$ & $1.19 \pm 0.15$ & $0.77 \pm 0.12$ & $0.69 \pm 0.09$ & $0.82 \pm 0.12$ \\
\hline Pancreas & $0.89 \pm 0.15$ & $0.93 \pm 0.09$ & $0.96 \pm 0.11$ & $0.86 \pm 0.15$ & $0.79 \pm 0.09$ & $0.81 \pm 0.14$ \\
\hline Kidney & $1.17 \pm 0.18$ & $1.31 \pm 0.17$ & $1.37 \pm 0.14$ & $1.02 \pm 0.11$ & $0.93 \pm 0.13$ & $0.98 \pm 0.12$ \\
\hline
\end{tabular}

Values are means $\pm \mathrm{SEM}, n=7$ per group. If ANOVA $P<0.05$, post hoc test analysis was performed. AU, arbitrary units; eEF2; elongation factor 2; elF, eukaryotic initiation factor; HP, high protein; LP, low protein; LP+L, LP supplemented with leucine.

a

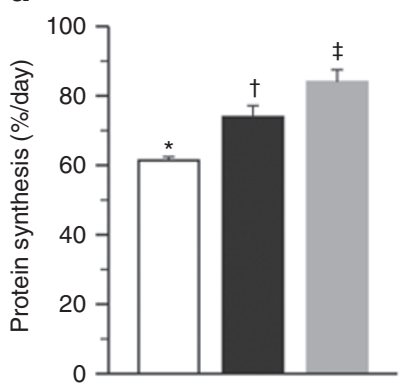

C

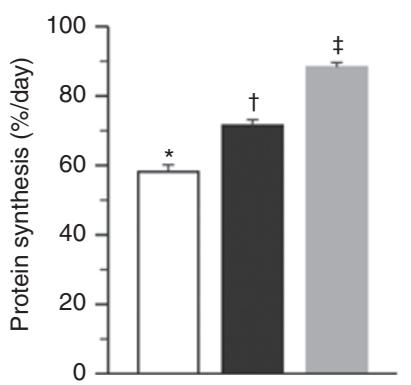

b

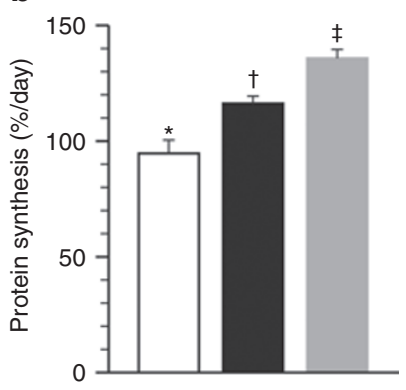

d

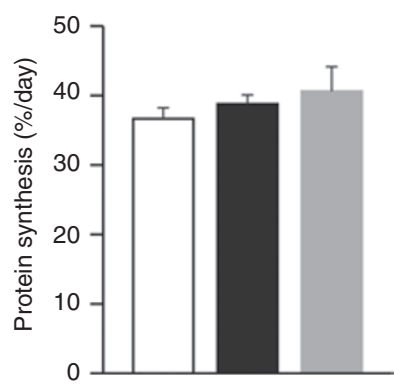

Figure 7. PS rates in (a) liver, (b) pancreas, (c) jejunum, and (d) kidney of piglets fed LP (open bars), LP+L (black bars), or HP (gray bars) diets. Values are means $\pm \mathrm{SEM}, n=7-10$ per treatment. Means without a common symbol differ, $P<0.05$. HP, high protein; $L P$, low protein; $L P+L$, LP supplemented with leucine; PS, protein synthesis.

with raptor, which elicits increased phosphorylation of these two mTOR substrates. These results are consistent with cell culture studies that showed that, for mTORC1 to phosphorylate S6K1 and 4EBP1, raptor has to bind to them through their TOR signaling motif $(32,33)$. We did not find a leucine effect on raptor association with mTOR or PRAS40, which could be due to a transient nature of their interaction in vivo. A leucine-induced increase in S6K1 and 4EBP1 phosphorylation was also observed in muscles with different fiber types and visceral tissues, except kidney. Increased 4EBP1 phosphorylation leads to decreased association with eIF4E, allowing active eIF4G•eIF4E complex formation (31). In this study, we found that leucine supplementation reduced 4EBP1•eIF4E complex formation and enhanced eIF4G•eIF4E complex formation.

In this study, plasma glutamine levels were elevated in the $\mathrm{LP}+\mathrm{L}$ group as compared with the LP group, suggesting de novo synthesis from exogenous leucine. Cell culture studies suggest that glutamine is needed for leucine-induced activation of mTORC1 (35), and thus, together with leucine, glutamine plays a crucial role in the regulation of PS.

Another potential signaling pathway mediating the leucineinduced stimulation of PS is the eIF2 pathway (22). In this study, we examined phosphorylation of eIF2 $\alpha$, an inhibitor and key player in this pathway. We found no effect of leucine on eIF2 $\alpha$ phosphorylation in any tissue studied. This result is consistent with the notion that leucine does not directly affect 
Table 3. Composition of experimental diets

\begin{tabular}{|c|c|c|c|}
\hline & LP & $\mathrm{LP}+\mathrm{L}$ & $\mathrm{HP}$ \\
\hline & \multicolumn{3}{|c|}{$\%$ of premix } \\
\hline \multicolumn{4}{|l|}{ Ingredients } \\
\hline Whey protein ${ }^{\mathrm{a}}$ & 8.6 & 8.7 & 52 \\
\hline Lactose $^{b}$ & 3.0 & 3.2 & 2.9 \\
\hline Fat Pak $80^{c}$ & 40.0 & 38.0 & 17 \\
\hline Water & 44.0 & 42.0 & 24 \\
\hline Vitamin premix ${ }^{d}$ & 0.35 & 0.35 & 0.35 \\
\hline Trace mineral premix ${ }^{d}$ & 0.25 & 0.25 & 0.25 \\
\hline Xanthan gum ${ }^{d}$ & 1.0 & 1.0 & 1.0 \\
\hline Dicalcium & 3.0 & 3.0 & 2.3 \\
\hline $\mathrm{MgSO}_{4}$ & 0.01 & 0.01 & 0.01 \\
\hline $\mathrm{KCl}$ & 0.01 & 0.01 & 0.01 \\
\hline \multicolumn{4}{|l|}{ Nutritional composition ${ }^{\mathrm{e}}$} \\
\hline Energy (kJ) & 14,120 & 14,120 & 14,120 \\
\hline Protein \% & 8.3 & 8.3 & 42 \\
\hline Fat $\%$ & 32 & 31 & 16 \\
\hline Lactose \% & 6.0 & 6.0 & 6.0 \\
\hline Leucine \% & 0.68 & 4.0 & 4.0 \\
\hline \multicolumn{4}{|c|}{$H P$, high protein; $L P$, low protein; $L P+L, L P$ supplemented with leucine. } \\
\hline \multicolumn{4}{|c|}{$\begin{array}{l}\text { ailmar } 8000 \text { (Hilmar ingredients): amino acid profile of whey, g/100 g whey: } \\
\text { alanine, 2.7; arginine, 2.2; aspartic acid, } 8.8 ; \text { cystine/cysteine, 1.7; glutamic acid, 14.0; } \\
\text { glycine, 1.5; histidine, 1.5; hydroxyproline, <0.1; isoleucine, 4.8; leucine, 9.1; lysine, 7.3; } \\
\text { methionine, 1.7; phenylalanine, 2.7; proline, 6.2; serine, 4.8; threonine, 4.5; tryptophan, } \\
\text { 1.2; tyrosine, 2.3; valine, 4.7. }\end{array}$} \\
\hline \multicolumn{4}{|c|}{ bInternational Ingredient Corporation. } \\
\hline \multicolumn{4}{|l|}{ 'MSC Company. } \\
\hline \multicolumn{4}{|c|}{ 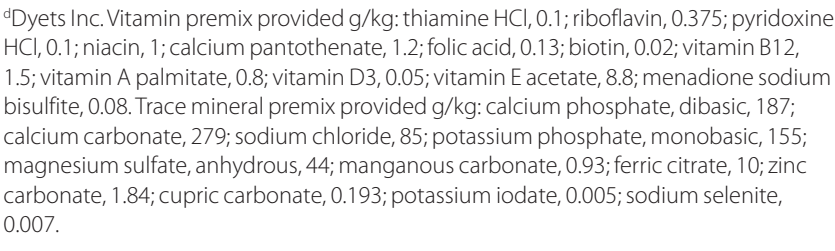 } \\
\hline${ }^{e} \mathrm{C} a l c u l a t e d$ nutrient compos & & & \\
\hline
\end{tabular}

eIF2 $\alpha$ phosphorylation, but eIF $2 \alpha$ phosphorylation status is affected by essential AA deficiency (36).

The elongation process in mRNA translation is another crucial step in the PS process (23). In cell culture studies, AAs, especially leucine, activate eEF2, a marker for peptide chain elongation, by dephophorylation (37). Thus, we determined whether leucine has similar effects in vivo. As in our previous study (16), leucine had no effect on eEF2 phosphorylation in any tissue studied. This suggests that regulation of elongation by AAs in vivo is complex and may differ from responses found in vitro.

In summary, 24-h enteral leucine supplementation of an LP-formula diet enhanced PS in most tissues of neonatal pigs in an mTORC1-dependent fashion. Although the leucineinduced increase in PS was less than that achieved with a HP diet, the results of our study suggest that leucine supplementation may have a beneficial effect on neonatal growth. Further studies are required to better understand the role of leucine and $\mathrm{BCAA}$ in the regulation of neonatal growth.

\section{MATERIALS AND METHODS}

\section{Animals}

Sows and piglets were managed as previously described $(14,15)$. After birth, piglets suckled ad libitum and were not given supplemental creep feed. At $2 \mathrm{~d}$ of age, indwelling catheters were surgically inserted into the jugular vein and carotid artery (38). The Animal Care and Use Committee of Baylor College of Medicine approved all experimental procedures. This study was conducted in accordance with the National Research Council's Guide for the Care and Use of Laboratory Animals.

\section{Treatments and Infusion}

Overnight fasted 5-d-old piglets $(2.3 \pm 0.1 \mathrm{~kg})$ were randomly assigned to one of the three dietary treatment groups receiving $\mathrm{LP}, \mathrm{LP}+\mathrm{L}$, or $\mathrm{HP}$ diets (Table $3 ; n=7-10$ pigs). The $\mathrm{LP}+\mathrm{L}$ diet provided an equivalent amount of leucine as the HP diet. All animals were gavage fed at a rate of $40 \mathrm{ml} \cdot \mathrm{kg}^{-1}$ at time $0 \mathrm{~min}$ and every $4 \mathrm{~h}$ for $24 \mathrm{~h}$; the feeding was administered over a 15-min period. Protein provided in the meal was 0.83 and $3.33 \mathrm{~g} \cdot \mathrm{kg}$ body weight $(\mathrm{wt})^{-1}$ for the LP and HP diets, respectively. Diets were isocaloric and contained the same lactose level. Blood samples were collected at intervals after feeding initiation for measurement of individual plasma AAs, insulin, and glucose concentrations. At $25 \mathrm{~h}$, piglets were injected with $\mathrm{L}\left[4{ }^{3} \mathrm{H}\right]$ phenylalanine to measure PS and killed $30 \mathrm{~min}$ later. Samples of longissimus dorsi, gastrocnemius, and masseter muscles, heart, liver, pancreas, kidney, and jejunum were obtained for measurements of PS rate and nutrientsignaling activation.

\section{Plasma Hormones and Substrate Assays}

Blood glucose concentrations were analyzed using a YSI 2300 STAT Plus (Yellow Springs Instruments, Yellow Springs, OH). Plasma total branched-chain AAs (BCAAs) were analyzed by rapid enzymatic kinetic assay (39). Individual AAs were measured by highperformance liquid chromatography (PICO-TAG reverse-phase column; Waters, Milford, MA) (40). Plasma radioimmunoreactive insulin concentrations were measured using a porcine insulin radioimmunoassay kit (Linco, St. Louis, MO).

\section{Tissue PS In Vivo}

Fractional rates of PS were measured with a flooding dose of $1.5 \mathrm{mmol} \cdot \mathrm{kg}$ body $\mathrm{wt}^{-1}$ of $\mathrm{L}\left[4{ }^{-3} \mathrm{H}\right]$ phenylalanine $\left(18.5 \mathrm{MBq} \cdot \mathrm{kg}^{-1}\right.$ body weight; American Radiolabeled Chemicals, St. Louis, MO) (41). Piglets were killed $90 \mathrm{~min}$ after the last meal because our previous meal-feeding study (42) showed increased PS from 0.5 to $2 \mathrm{~h}$ after the meal. Tissue samples were immediately frozen in liquid nitrogen and stored at $-70^{\circ} \mathrm{C}$ until analyzed.

\section{Protein Immunoblot Analysis}

Proteins from tissue homogenates were separated on polyacrylamide gels (polyacrylamide gel electrophoresis). Samples were run at the same time on triple-wide gels to eliminate interassay variation. Proteins were electrophoretically transferred to polyvinylidene difluoride transfer membranes (Pall Corporation, Pensacola, FL), incubated with primary antibodies, washed, and exposed to secondary antibody (16).

For normalization, immunoblottings performed with antiphosphospecific antibodies were stripped and reprobed with corresponding nonphospho-specific antibodies. Blots were visualized and analyzed using a ChemiDoc-It Imaging System (UVP, Upland, CA). Primary antibodies were PKB (total and $\mathrm{Ser}^{473}$, Cell Signaling Technology, Danvers, MA), mTOR (total and Ser ${ }^{2448}$, Cell Signaling), PRAS40 (Total and Thr ${ }^{246}$, Cell Signaling), 4EBP1 (total, Bethyl Laboratories, Montgomery, TX, and Thr ${ }^{70}$, Cell Signaling), eIF4G (total and Ser ${ }^{180}$, Cell Signaling), S6K1 (total and $\mathrm{Thr}^{398}$, Cell Signaling), eIF2a (Total and Ser ${ }^{51}$, Cell Signaling), and eEF2 (Total and $\mathrm{Thr}^{56}$, Cell Signaling).

\section{Quantification of Protein-Protein Interaction}

eIF4E•eIF4G and eIF4E•4EBP1 complexes were immunoprecipitated using an anti-eIF4E monoclonal antibody (Dr. Leonard Jefferson, Penn State University College of Medicine, Hershey, PA) followed by immunoblotting with 4EBP1 (Bethyl Laboratories) or eIF4G antibodies (16). For analysis of protein-protein interaction of members of mTORC1, homogenates were immunoprecipitated using an antiraptor 
antibody (Cell Signaling) (43). Western blot analyses using mTOR, S6K1, 4EBP1, and PRAS40 were conducted to determine interaction with raptor. Protein-protein interaction was normalized by eIF4E or raptor abundance.

\section{Calculations and Statistics}

Fractional rates of PS (Ks, percentage of protein mass synthesized in a day) were calculated as Ks $(\% / d)=\left[\left(S_{b} / S_{a}\right) \times(1,440 / t)\right] \times 100$, where $\mathrm{S}_{\mathrm{b}}$ (in dpm.nmol ${ }^{-1}$ ) is the specific radioactivity of the protein-bound phenylalanine, $\mathrm{S}_{\mathrm{a}}\left(\mathrm{in} \cdot \mathrm{nmol}^{-1}\right.$ ) is the specific radioactivity of the tissuefree phenylalanine, $t$ is labeling time in $\mathrm{min}$, and 1,440 is the min-to-d conversion (44).

Statistical analysis was carried out in SPSS (Version 17.0). A protected post hoc least significant differences $t$ test was used to determine differences between groups if, after performing a one-way ANOVA, a significant difference was found. Analysis of glucose and insulin across time was carried out with SPSS General Linear Model using repeated-measures test for within-subject effects. Differences of $<0.05$ were considered significant, and data are presented as means \pm SEM.

\section{ACKNOWLEDGMENTS}

We thank Rosemarie Almonaci for technical assistance, Jerome Stubblefield and Rickey Bryant for care of animals, E. O'Brian Smith for statistical assistance, Adam Gillum for graphics, and Linda Kemper for secretarial assistance.

\section{STATEMENT OF FINANCIAL SUPPORT}

This study was supported by the Ajinomoto Amino Acid Research Program, National Institutes of Health (NIH) R01 AR44474, NIH KO8 AR051563, and US Department of Agriculture/ARS 6250-510000-055.

\section{REFERENCES}

1. Hack M, Horbar JD, Malloy MH, Tyson JE, Wright E, Wright L. Very low birth weight outcomes of the National Institute of Child Health and Human Development Neonatal Network. Pediatrics 1991;87:587-97.

2. Hack M, Fanaroff AA. Outcomes of extremely-low-birth-weight infants between 1982 and 1988. N Engl J Med 1989;321:1642-7.

3. Ehrenkranz RA, Younes N, Lemons JA, et al. Longitudinal growth of hospitalized very low birth weight infants. Pediatrics 1999;104(2 Pt 1):280-9.

4. Ford GW, Doyle LW, Davis NM, Callanan C. Very low birth weight and growth into adolescence. Arch Pediatr Adolesc Med 2000;154:778-84.

5. Peralta-Carcelen M, Jackson DS, Goran MI, Royal SA, Mayo MS, Nelson KG. Growth of adolescents who were born at extremely low birth weight without major disability. J Pediatr 2000;136:633-40.

6. Johnson JD, Albritton WL, Sunshine P. Hyperammonemia accompanying parenteral nutrition in newborn infants. J Pediatr 1972;81:154-61.

7. Abdelhamid AE, Chuang SL, Hayes P, Fell JM. In vitro cow's milk proteinspecific inflammatory and regulatory cytokine responses in preterm infants with necrotizing enterocolitis and sepsis. Pediatr Res 2011;69:165-9.

8. Davis TA, Burrin DG, Fiorotto ML, Nguyen HV. Protein synthesis in skeletal muscle and jejunum is more responsive to feeding in 7-than in 26-dayold pigs. Am J Physiol 1996;270(5 Pt 1):E802-9.

9. O'Connor PM, Bush JA, Suryawan A, Nguyen HV, Davis TA. Insulin and amino acids independently stimulate skeletal muscle protein synthesis in neonatal pigs. Am J Physiol Endocrinol Metab 2003;284:E110-9.

10. Davis TA, Fiorotto ML, Burrin DG, et al. Stimulation of protein synthesis by both insulin and amino acids is unique to skeletal muscle in neonatal pigs. Am J Physiol Endocrinol Metab 2002;282:E880-90.

11. Anthony JC, Yoshizawa F, Anthony TG, Vary TC, Jefferson LS, Kimball SR. Leucine stimulates translation initiation in skeletal muscle of postabsorptive rats via a rapamycin-sensitive pathway. J Nutr 2000;130:2413-9.

12. Anthony JC, Anthony TG, Kimball SR, Vary TC, Jefferson LS. Orally administered leucine stimulates protein synthesis in skeletal muscle of postabsorptive rats in association with increased eIF4F formation. J Nutr 2000;130:139-45.

13. Bolster DR, Vary TC, Kimball SR, Jefferson LS. Leucine regulates translation initiation in rat skeletal muscle via enhanced eIF4G phosphorylation. J Nutr 2004;134:1704-10.
14. Escobar J, Frank JW, Suryawan A, et al. Physiological rise in plasma leucine stimulates muscle protein synthesis in neonatal pigs by enhancing translation initiation factor activation. Am J Physiol Endocrinol Metab 2005;288:E914-21.

15. Escobar J, Frank JW, Suryawan A, et al. Regulation of cardiac and skeletal muscle protein synthesis by individual branched-chain amino acids in neonatal pigs. Am J Physiol Endocrinol Metab 2006;290:E612-21.

16. Suryawan A, Jeyapalan AS, Orellana RA, Wilson FA, Nguyen HV, Davis TA. Leucine stimulates protein synthesis in skeletal muscle of neonatal pigs by enhancing mTORC1 activation. Am J Physiol Endocrinol Metab 2008;295:E868-75.

17. Wilson FA, Suryawan A, Gazzaneo MC, Orellana RA, Nguyen HV, Davis TA. Stimulation of muscle protein synthesis by prolonged parenteral infusion of leucine is dependent on amino acid availability in neonatal pigs. J Nutr 2010;140:264-70.

18. Greiwe JS, Kwon G, McDaniel ML, Semenkovich CF. Leucine and insulin activate p70 S6 kinase through different pathways in human skeletal muscle. Am J Physiol Endocrinol Metab 2001;281:E466-71.

19. Corradetti MN, Guan KL. Upstream of the mammalian target of rapamycin: do all roads pass through mTOR? Oncogene 2006;25:6347-60.

20. Dennis MD, Baum JI, Kimball SR, Jefferson LS. Mechanisms involved in the coordinate regulation of mTORC1 by insulin and amino acids. J Biol Chem 2011;286:8287-96.

21. Proud CG. mTORC1 signalling and mRNA translation. Biochem Soc Trans 2009;37(Pt 1):227-31.

22. Kimball SR. Eukaryotic initiation factor eIF2. Int J Biochem Cell Biol 1999;31:25-9.

23. Browne GJ, Proud CG. Regulation of peptide-chain elongation in mammalian cells. Eur J Biochem 2002;269:5360-8.

24. Murgas Torrazza R, Suryawan A, Gazzaneo MC, et al. Leucine supplementation of a low-protein meal increases skeletal muscle and visceral tissue protein synthesis in neonatal pigs by stimulating mTOR-dependent translation initiation. J Nutr 2010;140:2145-52.

25. Vlaardingerbroek $\mathrm{H}$, van Goudoever JB, van den Akker $\mathrm{CH}$. Initial nutritional management of the preterm infant. Early Hum Dev 2009; 85:691-5.

26. Zello GA, Menendez CE, Rafii M, et al. Minimum protein intake for the preterm neonate determined by protein and amino acid kinetics. Pediatr Res 2003;53:338-44.

27. Suryawan A, Hawes JW, Harris RA, Shimomura Y, Jenkins AE, Hutson SM. A molecular model of human branched-chain amino acid metabolism. Am J Clin Nutr 1998;68:72-81.

28. Drummond MJ, Rasmussen BB. Leucine-enriched nutrients and the regulation of mammalian target of rapamycin signalling and human skeletal muscle protein synthesis. Curr Opin Clin Nutr Metab Care 2008;11:222-6.

29. Tessari P, Garibotto G. Interorgan amino acid exchange. Curr Opin Clin Nutr Metab Care 2000;3:51-7.

30. Proud CG. Regulation of protein synthesis by insulin. Biochem Soc Trans 2006;34(Pt 2):213-6.

31. Proud CG. mTOR-mediated regulation of translation factors by amino acids. Biochem Biophys Res Commun 2004;313:429-36.

32. Nojima $\mathrm{H}$, Tokunaga $\mathrm{C}$, Eguchi $\mathrm{S}$, et al. The mammalian target of rapamycin (mTOR) partner, raptor, binds the mTOR substrates p70 S6 kinase and 4E-BP1 through their TOR signaling (TOS) motif. J Biol Chem 2003; 278:15461-4.

33. Schalm SS, Fingar DC, Sabatini DM, Blenis J. TOS motif-mediated raptor binding regulates $4 \mathrm{E}-\mathrm{BP} 1$ multisite phosphorylation and function. Curr Biol 2003;13:797-806

34. Wang L, Harris TE, Roth RA, Lawrence JC Jr. PRAS40 regulates mTORC1 kinase activity by functioning as a direct inhibitor of substrate binding. J Biol Chem 2007;282:20036-44.

35. Nicklin P, Bergman P, Zhang B, et al. Bidirectional transport of amino acids regulates mTOR and autophagy. Cell 2009;136:521-34.

36. Gietzen DW, Rogers QR. Nutritional homeostasis and indispensable amino acid sensing: a new solution to an old puzzle. Trends Neurosci 2006;29:91-9.

37. Nakai N, Kawano F, Terada M, Oke Y, Ohira T, Ohira Y. Effects of peroxisome proliferator-activated receptor alpha (PPARalpha) agonists on 
leucine-induced phosphorylation of translational targets in $\mathrm{C} 2 \mathrm{C} 12$ cells. Biochim Biophys Acta 2008;1780:1101-5.

38. Wray-Cahen D, Beckett PR, Nguyen HV, Davis TA. Insulin-stimulated amino acid utilization during glucose and amino acid clamps decreases with development. Am J Physiol 1997;273(2 Pt 1):E305-14.

39. Beckett PR, Hardin DS, Davis TA, Nguyen HV, Wray-Cahen D, Copeland KC. Spectrophometric assay for measuring branchedchain amino acid concentrations: application for measuring the sensitivity of protein metabolism to insulin. Anal Biochem 1996;240: 48-53.

40. Davis TA, Fiorotto ML, Nguyen HV, Reeds PJ. Enhanced response of muscle protein synthesis and plasma insulin to food intake in suckled rats. Am J Physiol 1993;265(2 Pt 2):R334-40.
41. Garlick PJ, McNurlan MA, Preedy VR. A rapid and convenient technique for measuring the rate of protein synthesis in tissues by injection of $[3 \mathrm{H}]$ phenylalanine. Biochem J 1980;192:719-23.

42. Wilson FA, Suryawan A, Orellana RA, et al. Feeding rapidly stimulates protein synthesis in skeletal muscle of neonatal pigs by enhancing translation initiation. J Nutr 2009;139:1873-80.

43. Williamson DL, Bolster DR, Kimball SR, Jefferson LS. Time course changes in signaling pathways and protein synthesis in $\mathrm{C} 2 \mathrm{C} 12$ myotubes following AMPK activation by AICAR. Am J Physiol Endocrinol Metab 2006;291:E80-9.

44. Davis TA, Fiorotto ML, Nguyen HV, Burrin DG. Aminoacyl-tRNA and tissue free amino acid pools are equilibrated after a flooding dose of phenylalanine. Am J Physiol 1999;277(1 Pt 1):E103-9. 